\title{
The Relations of TNF- $\alpha$, CRP and Lipid Profile with Carotid Intima-Media Thickness (CIMT) in OBESE Adolescents
}

\author{
Roedi Irawan ${ }^{1}$, Nur Aisiyah Widjaja ${ }^{1}$, Meta Hanindita Herdiana ${ }^{1}$, \\ Meity Ardiana ${ }^{2}$, Rendi Aji Prihaningtyas ${ }^{1}$ \\ ${ }^{1}$ Department of Pediatrics, ${ }^{2}$ Department of Cardiology and Vascular Medicine, Faculty of Medicine, \\ Universitas Airlangga/Dr. Soetomo Hospital, Surabaya
}

\begin{abstract}
Background: Obesity is a health problem, causes serious complications. The mechanism of fat accumulation in the initial process of atherosclerosis is still unclear. The process occurs due to chronic inflammation where the indicator of atherosclerosis that related to inflammatory processes, such as levels of C-reactive protein (CRP) and tumor necrosis factor alpha (TNF- $\alpha$ )in the blood are higher in children with obesity.

Purpose: To examine the relationship of TNF- $\alpha$, hsCRP and lipid profile with CIMT in obese adolescents.

Method: A cross sectional study was conducted on obese adolescents in Dr. Soetomo Hospital Child Health Unit from January until September 2018. Measurements of TNF- $\alpha$, hsCRP and lipid profile were examine using ELISA method. CIMT was obtained through carotid ultrasound. TNF- $\alpha$ correlation, hsCRP and lipid profile with CIMT were analyzed using Pearson and Spearman Rho with significant value of $\mathrm{P}<0.05$. Logistic regression analysis was carried out to determine the effect of cardiovascular disease risk factors on CIMT.
\end{abstract}

Result: 59 adolescents with central obesity were obtained, consisting of $32(54.2 \%)$ boys and 27 (45.8\%) girls. Total of $38(64.4 \%)$ adolescents with dyslipidemia. There was no correlation between TNF- $\alpha$, hsCRP, lipid profile and CIMT. The diameter of common carotid artery had a positive correlation with hsCRP $(\mathrm{r}=0.284 ; \mathrm{P}=0.029)$. In girls, hsCRP had a positive correlation with the diameter of the left common carotid artery $(\mathrm{r}=0.533 ; \mathrm{P}=0.004)$. This correlation was not found in boys.

Conclusions: There was no correlation between TNF- $\alpha$, hsCRP, lipid profile and CIMT.

Keywords: Carotid intima-media thickness, hsCRP, Obesity, Llipid profile, TNF- $\alpha$.

\section{Introduction}

Obesity is a health problem throughout the world, causes serious short-term and long-term complications. In 2020 , it is predicted that there will be an increase

\section{Corresponding Author:}

\section{Roedi Irawan, MD}

Department of Child Health, Faculty of Medicine, Universitas Airlangga, Indonesia

Tel: +62-898-9642-044

Fax : 031-5501748

e-mail: roedi.dr.rsds@gmail.com in the prevalence of cardiovascular disease by up to $16 \%$ and deaths from cardiovascular disease by $19 \%$ in adults aged $35-50$ years and atherosclerosis. ${ }^{1}$ Until now, the mechanism of fat accumulation in the initial process of atherosclerosis is still unclear, suspected the process occurs due to chronic inflammation. Obese children have a higher indicator of atherosclerosis than children without obesity. These indicators are related to inflammatory processes, such as levels of C-reactive protein (CRP) and tumor necrosis factor alpha (TNF- $\alpha)$ in the blood. ${ }^{2,3)}$ Now, the combination of measurement of the media layer and intima in the communic carotid artery is used for early identification of systemic atherosclerosis. $^{4)}$ Obese children have higher carotid 
intima-media thickness (CIMT) values than controls and are associated with higher BMI, waist circumference, triglyceride levels, cholesterol, LDL cholesterol and lower HDL cholesterol. ${ }^{5}$ This study were conducted to examine the relationship of TNF- $\alpha$, hsCRP and lipid profile with CIMT in obese adolescents.

\section{Materials and Method}

A cross-sectional study conducted at the Pediatric Departement, Dr. Soetomo General Hospital from January until September 2018. Inclusion criteria are adolescents aged 12-18 years with Body mass index $(\mathrm{BMI})>\mathrm{P} 9_{5}$ of $\mathrm{CDC}$ charts. Exclusion criteria included: corticosteroid consumption within 6 months prior to study, dyslipidemia medication in 3 months prior to study, antibiotics, hormonal therapy, smoking, alcohol consumption, infection and suffering immune disorders or endocrine disorders. Data on physical activity and food intake were obtained by food recall on weekdays and holidays.

Anthropometric examinations were carried out by trained health personnels. Body weight was measured without shoes, using clothes weighing a maximum of $0.1 \mathrm{~kg}$ and without other accessories using digital scale (Seca, Germany). Body height was measured in an upright position, without shoes or head coverings using stadiometer (Seca, Germany).BMI was calculated by dividing body weight in $\mathrm{kg}$ with height in meters squared.

TNF- $\alpha$, hsCRP and lipid were measure using ELISA method (in ng/L). Triglyceride is measured using TG-N Kit Autosera S (Sekisui Medical Co., Ltd., Japan), while LDL cholesterol, HDL and total cholesterol were measured using Cholestest ${ }$ LDL, Cholestest ${ }^{\circledR N}$ HDL and Pureauto®S CHO-N (Sekisui Medical Co., Ltd., Japan). Dyslipidemia was established ifone of the cholesterol, HDL, LDL and triglyceride levels were increased as recommended by NCPE and the American Academy of Pediatrics.

CIMT was obtained by carotid ultrasound using a neck ultrasound (Toshiba, Japan), measured on the back wall of the left carotid artery to obtain atherosclerotic plaques, characterized by protrusion of blood vessel walls into the blood vessel lumen by $>50 \%$ of the intimamedia layer in the blood vessels. ${ }^{\text {) }}$

Statistical analysis were conducted using SPSS Statistics 21, including average value, drink value and maximum were analyzed using quantitative parameters. Correlation of TNF- $\alpha$, hsCRP, lipid profile with CIMT and left internal carotid artery diameter were analyzed using bivariate analysis (significance at $\mathrm{P}$ value $<0.05$ ). Normal distribution were obtained. Pearson correlation carried out if the distribution were normal, otherwise Spearman's rho would be carried out.Quantitative parameters (CIMT, lipid profile levels, TNF- $\alpha$ and hsCRP) were analyzed in each group for distribution using Shapiro-Wilk test (significant at $p$ value $<0.05$ ).

\section{Results}

A total of 59 adolescents with central obesity were obtained, consisting of $32(54.2 \%)$ boys and 27 (45.8\%) girls, meanwhile 38 (64.4\%) adolescents were dyslipidemia. Table 1 lists characteristics of the subjects.

There were no significant differences between obese adolescents with dyslipidemia according to sex $(p=0.057)$ and there were no significant differences in obese adolescents with hypertriglycerides by sex (Table 2).

The average TNF- $\alpha$ level in the obese group with dyslipidemia was $149.16 \mathrm{ng} / \mathrm{l}$, while the nondyslipidemia group was $143.58 \mathrm{ng} / \mathrm{l}$. The average hsCRP level in the obese group with dyslipidemia was 2390.50 $\mathrm{ng} / \mathrm{ml}$, while the non-dyslipidemia group was 2161.06 $\mathrm{ng} / \mathrm{ml}$. The mean diameter of the left common carotid artery in the obese group with dyslipidemia was 6.51 $\mathrm{mm}$, while the non-dyslipidemia group was $6.46 \mathrm{~mm}$. Meanwhile, the average CIMT in the obese group with dyslipidemia was $0.54 \mathrm{~mm}$, while the non-dyslipidemia group was $0.47 \mathrm{~mm}$.

There was no correlation between hsCRP and CIMT ( $\mathrm{r}=0.072 ; \mathrm{P}=0.589$ ) but hsCRP had a positive correlation with the left common carotid artery diameter $(\mathrm{r}=0.284 ; \mathrm{P}=0.029)$. There was no correlation between TNF- $\alpha$ and the diameter of the common carotid artery or CIMT ( $\mathrm{r}=-0.057 ; \mathrm{P}=0.669 ; \mathrm{r}=-0,089 ; \mathrm{P}=0.501)$. There was no correlation between cholesterol, HDL, LDL and triglycerides with the diameter of the sininstra communic carotid artery $(\mathrm{r}=-0.209 ; \mathrm{P}=0.113 ; \mathrm{r}=-$ $0.221 ; \mathrm{P}=0.093 ; \mathrm{r}=-0.014 ; \mathrm{P}=0.289 ; \mathrm{r}=-0.0125 ; \mathrm{P}=0.346$ ). There was no correlation between Cholesterol, HDL, LDL and triglycerides with CIMT $(\mathrm{r}=0.154 ; \mathrm{P}=0.243$; $\mathrm{r}=0.079 ; \mathrm{P}=0.550 ; \mathrm{r}=0.168 ; \mathrm{P}=0.204 ; \mathrm{r}=0.058 ; \mathrm{P}=0.665)$.

There was no correlation between hsCRP and CIMT $(\mathrm{r}=0.072 ; \mathrm{P}=0.589)$. However, hsCRP had a positive 
correlation with the diameter of the left common carotid artery $(\mathrm{r}=0.284 ; \mathrm{P}=0.029)$. There was no correlation between TNF- $\alpha$ and the diameter of the common carotid artery or CIMT $(\mathrm{r}=-0.057 ; \mathrm{P}=0.669 ; \mathrm{r}=-0.089 ; \mathrm{P}=0.501)$. There was no correlation between cholesterol, HDL, LDL and triglycerides with the diameter of the sininstra communic carotid artery $(\mathrm{r}=-0.209 ; \mathrm{P}=0.113 ; \mathrm{r}=-$ $0.221 ; \mathrm{P}=0.093 ; \mathrm{r}=-0.014 ; \mathrm{P}=0.289 ; \mathrm{r}=-0.0125 ; \mathrm{P}=0.346)$. There was no correlation between Cholesterol, HDL, LDL and triglycerides with $\operatorname{CIMT}(\mathrm{r}=0.154 ; \mathrm{P}=0.243$; $\mathrm{r}=0.079 ; \mathrm{P}=0.550 ; \mathrm{r}=0.168 ; \mathrm{P}=0.204 ; \mathrm{r}=0.058 ; \mathrm{P}=0.665)$ (Table 4).
There was a positive correlation of hsCRP with the sininstra communist carotid artery diameter in female subjects $\quad(\mathrm{r}=0.533 ; \mathrm{P}=0.004$ dan $\mathrm{r}=0.452 ; \mathrm{P}=0.018)$, but no correlation between hsCRP and CIMT $(\mathrm{r}=0.048 ; \mathrm{P}=0.811)($ Table 5$)$.

Table 6 shows no significant correlation between hsCRP and the diameter of left communist carotid artery and CIMT in boys. The effect of hsCRP on the diameter of left communist carotid artery has a model of regression with the common carotid artery diameter equation $=5,045+0.001 \mathrm{x}$ hsCRP in girls, but not found in boys.

Table 1. Characteristics of research subjects

\begin{tabular}{|c|c|}
\hline Variable & Amount (Percentage) \\
\hline \multicolumn{2}{|l|}{ Sex } \\
\hline Boy & $32(54.2)$ \\
\hline Girl & $27(45.8)$ \\
\hline \multicolumn{2}{|l|}{ Dyslipidemia } \\
\hline Yes & $38(64.4)$ \\
\hline No & $21(35.6)$ \\
\hline \multicolumn{2}{|l|}{ Hypertriglyceride } \\
\hline Yes & $13(22)$ \\
\hline No & $46(78)$ \\
\hline \multicolumn{2}{|l|}{ Mother's occupation } \\
\hline Employed & $36(61)$ \\
\hline \multirow[t]{2}{*}{ Unemployed } & $23(39)$ \\
\hline & Mean \\
\hline Weight $(\mathrm{kg})$ & $80.77(53.5-112)$ \\
\hline Height $(\mathrm{cm})$ & $158.76(140.8-175.5)$ \\
\hline Body mass index $\left(\mathrm{kg} / \mathrm{m}^{2}\right)$ & $31.99(26.6-41.13)$ \\
\hline TNF- $\alpha(n g / 1)$ & $147.17(20.63-337.11)$ \\
\hline hsCRP (ng/ml) & $2308.83(285.79-2941.37)$ \\
\hline Total cholesterol (mg/dl) & $176.13(119-278)$ \\
\hline $\mathrm{LDL}(\mathrm{mg} / \mathrm{dl})$ & $117.81(62-196)$ \\
\hline HDL (mg/dl) & $44.42(31-67)$ \\
\hline Triglyceride (mg/dl) & $118.11(30-343)$ \\
\hline CIMT (mm) & $0.516(0.32-0.82)$ \\
\hline Diameter of left common carotid artery (mm) & $6.49(4.5-10)$ \\
\hline \multicolumn{2}{|l|}{ Plaque in left common carotid artery } \\
\hline Negative & $59(100)$ \\
\hline Positive & $0(0)$ \\
\hline
\end{tabular}

TNF- $\alpha$, tumor necrosis factor alpha; hsCRP, high-sensitivity C-reactive protein; LDL, low density lipoprotein; HDL, high density lipoprotein; CIMT, carotid intima-media thickness. 
Table 2. The incidence of dyslipidemia and hypertension by sex

\begin{tabular}{|l|c|c|c|}
\hline Variable & Boys (n/\%) & Girls (n/\%) & P \\
\hline Dyslipidemia & $24(63.15)$ & $14(36.85)$ & 0.057 \\
\hline Hypertriglyceride & $9(69.23)$ & $4(30.77)$ & 0.181 \\
\hline
\end{tabular}

* significant

Table 3. Average hsCRP levels, TNF- $\alpha$, left common carotid artery diameter, CIMT in dyslipidemia.

\begin{tabular}{|l|c|c|}
\hline Variable & Dyslipidemia (n/\%) Mean & Non dyslipidemia Mean \\
\hline hsCRP $(\mathrm{ng} / \mathrm{ml})$ & 2390.50 & 2161.06 \\
\hline TNF- $\alpha$ (ng/l) & 149.16 & 143.58 \\
\hline Diameter of left common carotid artery (mm) & 6.51 & 6.46 \\
\hline CIMT (mm) & 0.54 & 0.47 \\
\hline
\end{tabular}

hsCRP, high-sensitivity C-reactive protein;TNF- $\alpha$, tumor necrosis factor alpha; CIMT, carotid intima-media thickness.

Table 4. Correlation between TNF- $\alpha$, hsCRP, lipid profile with diameter of left communic carotid artery and CIMT

\begin{tabular}{|l|c|c|c|c|c|c|}
\hline Variable & TNF- $\alpha$ & hs-CRP & LDL & HDL & Cholesterol & Triglycerides \\
\hline CIMT & & & & & & \\
r & -0.089 & 0.072 & 0.168 & 0.079 & 0.154 & 0.058 \\
P & 0.501 & 0.589 & 0.204 & 0.550 & 0.243 & 0.665 \\
\hline Diameter of left communist carotid artery & & & & & & \\
r & -0.057 & 0.284 & -0.014 & -0.221 & -0.209 & -0.0125 \\
P & 0.669 & $0.029^{*}$ & 0.289 & 0.093 & 0.113 & 0.346 \\
\hline
\end{tabular}

$* \mathrm{P}<0.05$ indicates statistical significance

TNF- $\alpha$, tumor necrosis factor alpha; hsCRP, high-sensitivity C-reactive protein; LDL, low density lipoprotein; HDL, high density lipoprotein; CIMT, carotid intima-media thickness.

Table 5. Correlation in female subjects

\begin{tabular}{|l|c|}
\hline Variable & hsCRP \\
\hline Diameter of left communist carotid artery & 0.452 \\
r & $0.018^{*}$ \\
P & \\
\hline CIMT & 0.048 \\
r & 0.811 \\
P & \\
\hline
\end{tabular}

$* \mathrm{P}<0.05$ indicates statistical significance

hsCRP, high-sensitivity C-reactive protein; CIMT, carotid intima-media thickness. 
Table 6. Correlation in male subjects

\begin{tabular}{|l|c|}
\hline Variable & hsCRP \\
\hline Diameter of left communist carotid artery & \\
r & 0.156 \\
P & 0.393 \\
\hline CIMT & \\
r & 0.118 \\
P & 0.522 \\
\hline
\end{tabular}

$* \mathrm{P}<0.05$ indicates statistical significance

hsCRP, high-sensitivity C-reactive protein; CIMT, carotid intima-media thickness.

\section{Discussion}

TNF- $\alpha$ is one of the main cytokines produced by fat tissue, especially monocytes, lymphocytes, adipose tissue and muscles. TNF- $\alpha$ activity increases the release of free fatty acids in adipocytes, blocks the synthesis of adipokine and interferes the phosphorylation of tyrosine residues in the first substrate of insulin receptors. TNF- $\alpha$ activates NF- $\kappa B$, lead to enhancement expression of adhesion molecules on the surface of endothelial cells and vascular smooth muscle cells, causing inflammation in adipose tissue, endothelial dysfunction and eventually atherogenesis. TNF- $\alpha$ involved in insulin resistance and atherosclerosis by increasing the production of $\mathrm{Th} 2$ cytokines (IL-4 and IL-5) and increase the expression of leptin and IL-6 in fat cells. IL- 6 stimulates acute phase protein production in the liver and increases CRP levels which lead to mild inflammation in endothelial cells, causing endothelialcell dysfunction, atherosclerosis and other cardiovascular complications.

CIMT is a structural marker of atherosclerosis. The combination of measurement of the media layer and intima in the communic carotid artery is used for early identification of systemic atherosclerosis now. ${ }^{4}$ ) The average CIMT size of Asian children is 0.469$0,476 \mathrm{~mm}^{7}{ }^{7}$ CIMT is associated with cardiovascular risk factors and the severity of atherosclerosis. Subjects with carotid plaque $>1.9 \mathrm{~mm}$ had a 2.8 -fold higher risk of cardiovascular events than subjects without carotid plaque (hazard ratio, 2.80; 95\% CI, 2.04-3.84). ${ }^{8}$ Plaque was not found in obese adolescents in this study.

In obesityoccurs a chronic inflammatory process, so obese children have a higher indicator of atherosclerosis than normal children that are related to the inflammatory process, such as levels of CRP in the blood. ${ }^{2)}$ Increasing of CRP levels and decrease of adiponectin indicate inflammatory process. The changes in CRP and adiponectin levels are associated with the increase of CIMT. ${ }^{9)}$ There is a positive correlation between CIMT and waist circumference with levels of TNF- $\alpha^{10)}$ and hsCRP ${ }^{11)}$. Studies in Indonesia stated that TNF- $\alpha$ levels did not differ significantly in obese and non-obese groups ${ }^{12)}$ which is in line with this research. But another study showed there was a positive correlation between obesity and an increase in CRP levels. ${ }^{13)}$

$31 \%$ of obese children with metabolic syndromes. ${ }^{14)}$ Dyslipidemia (impaired lipid profile) is a component of the metabolic syndrome and a risk factor for atherosclerosis. Dyslipidemia associated with obesity is characterized increase of triglyceride levels, decrease of HDL cholesterol levels and an increase in LDL cholesterol levels. ${ }^{15)}$ Silva et alstated HDL cholesterol levels had a negative correlation with CIMT. ${ }^{13)}$ CIMT is associated with LDL cholesterol levels and the ratio of $\mathrm{LDL} / \mathrm{HDL}$ cholesterol. ${ }^{16)}$ LDL cholesterol (OR; 1,325, 95\% CI; 1,046-1,821, $\mathrm{P}=0.033$ ) and HDL cholesterol (OR; 0.093, 95\% CI; 0.038-0,227, $\mathrm{P}<0.001$ ) are predictors of carotid plaques. ${ }^{16)}$ Other studies show that there is no correlation between blood fat levels and $\mathrm{CIMT}^{2}$ which is in line with this study.

Obese adolescents had thicker CIMT $(0.69 \mathrm{~mm})$ than normal adolescents $(0.38 \mathrm{~mm}){ }^{17)}$ The higher of BMI, the greater the thickness of CIMT. ${ }^{18)}$ There is a positive correlation between CIMT and body fat most commonly found in children with visceral obesity. ${ }^{13)}$ There was no association between visceral obesity as indicated by waist circumference with CIMT in this study which is in line with the study conducted by Song et al. ${ }^{19)}$ 
The relationship between blood fat levels and CIMT is still controversial. High level of triglyceride associated with the development of atherosclerosis, but the mechanism is unclear. CIMT is inversely proportional to triglyceride levels. ${ }^{7)}$

Studies show the relationship of the risk of cardiovascular disease is higher in girls than boys, ${ }^{20,21)}$ which is consistent with this study where hsCRP had a positive correlation with the left common carotid artery diameter $(\mathrm{r}=0.533 ; \mathrm{P}=0.004$ dan $\mathrm{r}=0.452 ; \mathrm{P}=0.018)$. The common carotid artery diameter equation $=5.045+$ $0.001 \mathrm{x}$ hsCRP in girls. This correlation were not found in boys.

The diameter of the common carotid artery had a positive correlation with hsCRP $(r=0.284 ; p=0.029)$. In girls, hsCRP had a positive correlation with the diameter of the left common carotid artery $(\mathrm{r}=0.533 ; \mathrm{P}=0.004$ and $\mathrm{r}=0.452 ; \mathrm{P}=0.018$ ) with the syninial common carotid artery diameter equation $=5.045+0.001 \mathrm{x}$ hsCRP, but not found in boys.

\section{Conclusion}

There was no correlation between TNF- $\alpha$, hCRP and lipid profile with CIMT.

\section{Conflict of Interest: None}

Ethical Clearance: This study were registered with ethical clearance number 0411/KEPK/VII/2018 issued by Ethical committee in health research of Dr. Soetomo General Hospital Surabaya.

Source of Funding: This study were funded by Airlangga University Research Fund

\section{References}

1. Daniels SR, Greer FR. Lipid screening and cardiovascular health in childhood. Pediatrics 2008;122:198.

2. Pyrzak B, Ruminska M, Majcher A, Wisniewska A, Brzewski M, Demkow U, dkk. Association of adiponectin gene G276T polymorphism with atherogenic indicators in obese children.Adv Exp Med Biol 2013;756:247-54.

3. Elulu MS, Patimah I, Khaza'ai H, Rahmat A, Abed Y. Obesity and inflammation: the linking mechanismand the complications. Arch Med Sci 2017; 13: 851-63.
4. Casella IB, Presti C, Porta RM, Sabbag CR, Bosch MA, Yamazaki Y. A practical protocol to measure common carotid artery intima-media thickness. Clinics (Sao Paulo). 2008;63:515-20.

5. Simsek E, Balta H, Balta Z, Dallar Z. Childhood obesity-related cardiovascular risk factors and carotid intima-media thickness.Turk $\mathrm{J}$ Pediatr 2010;52:602-11.

6. Juonala M, Viikari JS, Kahonen M, Solakiyi T, Helenius H, Jula A, dkk. Childhood levels of serum apolipoproteins B and A-I predict carotid intimamedia thickness and brachial endothelial function in adulthood. J Am Coll Cardiol 2008;52:293-9.

7. Whincup PH, Nightingale CM, Owen CG, Rapala A, Bhowruth DJ, Prescott MH, et. al. ethnic differences in carotid intima-media thicknessbetween UK children of black African-Caribbean andWhiteEuropean origin. Stroke 2012;43:1747-54.

8. Rundek T, Arif H, Boden-Albala B, Elkind MS, Paik MC, Sacco RL. Carotid plaque, a subclinical precursor of vascular events: the Northern Manhattan Study.Neurology 2008;70:1200-7.

9. Silva LR, Stefanello JM, Pizzi J, Timossi LS, Leite $\mathrm{N}$. Atherosclerosis subclinical and inflammatory markers in obese and nonobese children and adolescents.Rev Bras Epidemiol 2012;15:804-16.

10. de Oliviera R, Moraes TI, Cerda A, Hiroyuki M, Fajardo CM, Sousa MC, et al. ADIPOQ and IL6 variants are associated with a pro-inflammatory status in obeses with cardiometabolic dysfunction. Diabetology \& Metabolic Syndrome 2015;7:34.

11. Elkiran O, Yilmaz E, Koc M, Kamanli A, Ustundag $\mathrm{B}$, Ilha $\mathrm{N}$. The association between intima media thickness, central obesity and diastolic blood pressure in obese and overweight children: a cross-sectional school-based study.Int J Cardiol. 2013;165:528-32.

12. Hastuti P, Tasmini, Sadewa AH, Chornelia DM, Karita D. Level of adipokines and insulin resistance in obese Javanese population. J Med Sci 2017;49:56-63.

13. Silva LR, Cavaglieri C, Lopes WA, Pizzi J, Coelhoe-Silva MJC, Leite N. Endothelial wall thickness, cardiorespiratory fitness and inflammatory markers in obese and non-obese adolescents. Braz J Phys Ther 2014;18:47-55.

14. Arrigo T, Chirico V, Salpietro V, Munafo C, Ferrau V, Gitto E, et al. High-mobility group protein B1: 
a new biomarker of metabolic syndrome in obese children. European Journal of Endocrinology 2013;168:631-8.

15. Fernandez-Real J and Pickup J. Innate immunity, insulin resistance and type 2 diabetes. Diabetologia 2012;55:273-8.

16. Yang C, Sun Z, Li Y, Junping A, Sun Q, Tian Y. The correlation between serum lipid profile with carotid intima-media thickness and plaque. BMC Cardiovasc Disord 2014;14:181.

17. Fang J, Zhang JP, Luo CX, Yu XM. Carotid Intimamedia thickness in childhood and adolescent obesity relations to abdominal obesity, high triglyceride level and insulin resistance. Int J Med Sci 2010; 7:278-83.

18. Leite A, Santos A, Monteiro M, Gomes L, Veloso
M, Costa M. Impact of overweight and obesity in carotid intima-media thickness of portuguese adolescents.Acta Paediatr 2012;101:e115-21.

19. Song YM, Lee K, Sung J, Kim YS, Lee JY. Sexspecific relationships between adiposity and anthropometric measures and carotid intima-media thickness in Koreans: the Healthy Twin Study.Eur J Clin Nutr 2012;66:39-46.

20. Weberruß H, Pirzer R, Bohn B, Pozza RD, Netz $\mathrm{H}$, Oberhoffer R. Intima-media thickness and arterialfunction in obese and non-obese children. BMC Obes 2016;3:2.

21. Jaroch J, Loboz-Rudnicka M, Bociaga Z, Rzyckzowska B, Uchmanowicz I, Polariski J, et al.Impact of cardiovascular risk factors on carotid intima-media thickness: sex differences. Clinical Interventions in Aging 2016;11:721-31. 